Return to the Manage Active Submissions page at http://spie.org/app/submissions/tasks.aspx and approve or disapprove this submission. Your manuscript will not be published without this approval. Please contact author help@spie.org with any questions or concerns.

\title{
Developing of MERTIS as an advanced process from the study up to the flight model
}

\author{
G.Peter $^{1}$, Dr.J.Helbert ${ }^{2}$, Prof.H.Hiesinger ${ }^{3}$, Dr.I.Weber ${ }^{3}$, I.Walter ${ }^{1}$, Dr.G.Arnold ${ }^{2}$, T.Säuberlich ${ }^{1}$ \\ ${ }^{1}$ German Aerospace Center, Institute of Optical Sensor Systems, Rutherfordstrasse 2, 12489 Berlin \\ ${ }^{2}$ German Aerospace Center, Institute of Planetary Research, Rutherfordstrasse 2, 12489 Berlin \\ ${ }^{3}$ Westfaelische Wilhelms-Universität Muenster, Institut für Planetologie, Wilhelm-Klemm-Str. 10, \\ 48149 Muenster
}

\begin{abstract}
ESA's mission BepiColombo will be launched in 2016. MERTIS (Mercury Radiometer and Thermal imaging Spectrometer) is one of the key instruments. MERTIS is an imaging infrared spectrometer and radiometer using an uncooled detector technology with very small resources in terms of mass and power. The incentive of the MERTIS development is scientific requirements to study the surface composition and temperatures of Mercury under the extreme environmental condition at Mercury. Therefore, the state-of-the-art optical performance of MERTIS is unique. Components based on innovative technologies have been developed and qualified to realize the project. This approach required an advanced model philosophy and development process from the study up to the flight model completed in 2013. This paper describes the development process as well as challenges from the management and system engineering point of view up to a lessons learnt that lead to important conclusions.
\end{abstract}

Keywords: Infrared imaging spectrometer, BepiColombo, Micro-bolometer, project management, development costs

\section{INTRODUCTION}

In 2004 a new infrared spectrometer and radiometer for remote sensing of the Mercury has been proposed to ESA MERTIS for BepiColombo ${ }^{1}$. Now, in 2013, the MERTIS flight model (FM) is integrated, tested and calibrated successfully. It represents a state-of-the-art instrument with better optical performance as required in ${ }^{2,4}$ e.g. SNR (spectrometer) $>266 @ 8 \mu \mathrm{m}$, lower mass and power resources as expected (i.e. 3,1 kg and $<10 \mathrm{~W}$ ), developed on schedule within the required financial budget.

MERTIS' scientific goals are to infer rock-forming minerals, to map surface composition, and to study surface temperature variations on Mercury ${ }^{2-5,24,25}$. Required optical performances are analyzed as shown in ${ }^{16}$.

A brief description of the instrument design, applied technologies and performances is presented. The model philosophy is shown which has been extended beyond the required level from ESA. The objective was to reduce the development risk significantly with a low increase of development costs. An advanced on-board and on-ground software concept speeds up the development process having more time for the final calibration, which is one of the most important steps getting an optimized scientific optical performance.

Furthermore, a specific project organization had been established. The system design was developed by a technology oriented scientific institute. The verification and testing, however, was in the responsibility of an industrial company. The paper describes the development process, the costs, and what the entire team has learnt.

\section{DESIGN AND TECHNOLOGY}

As described in detail in ${ }^{7}$ MERTIS is a system with over ten miniaturized, highly integrated sub-systems, the optics, two IR detectors (bolometer and radiometer) and its read-out electronics, two actuators and two infrared (IR) emitters as inflight calibration devices, two baffles, several temperature sensors, as well as instrument controller including on-board software and power electronics both with cold redundancy. It is a "plug and play" instrument, which means there are only two interfaces, power and Spacewire ${ }^{26}$, few telecommands are needed to operate the instrument in a science mode. Several autonomous functions are implemented by on-board software, e.g. to operate at different temperatures without any user interactions. Table 1 summarizes the performance of the flight model. 
Return to the Manage Active Submissions page at http://spie.org/app/submissions/tasks.aspx and approve or disapprove this submission. Your manuscript will not be published without this approval. Please contact author_help@spie.org with any questions or concerns.

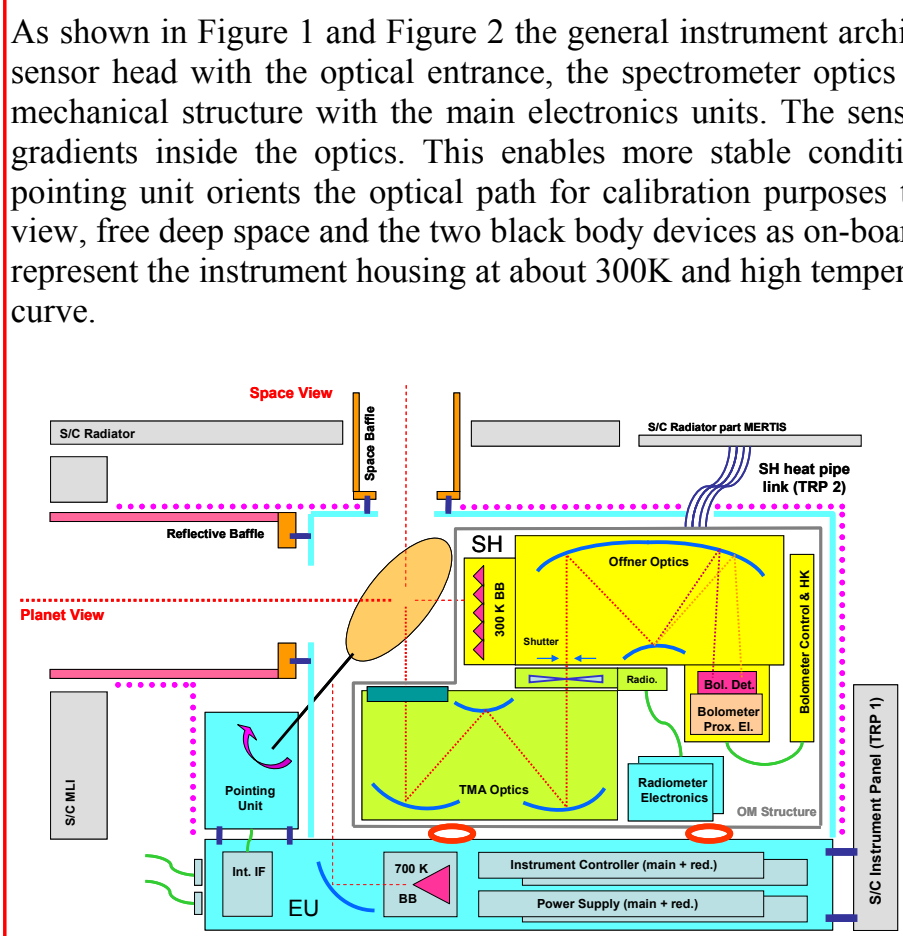

Figure 1. Block diagram

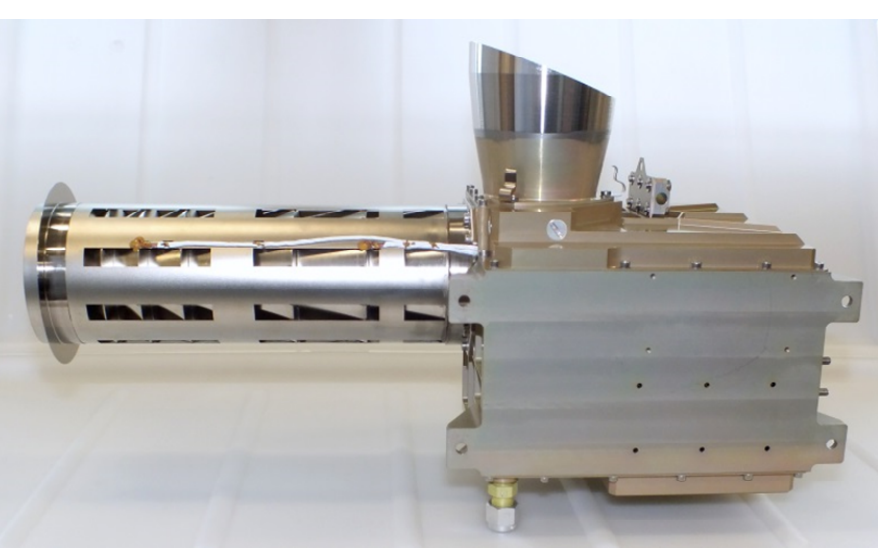

Figure 3. Flight model (FM) completed

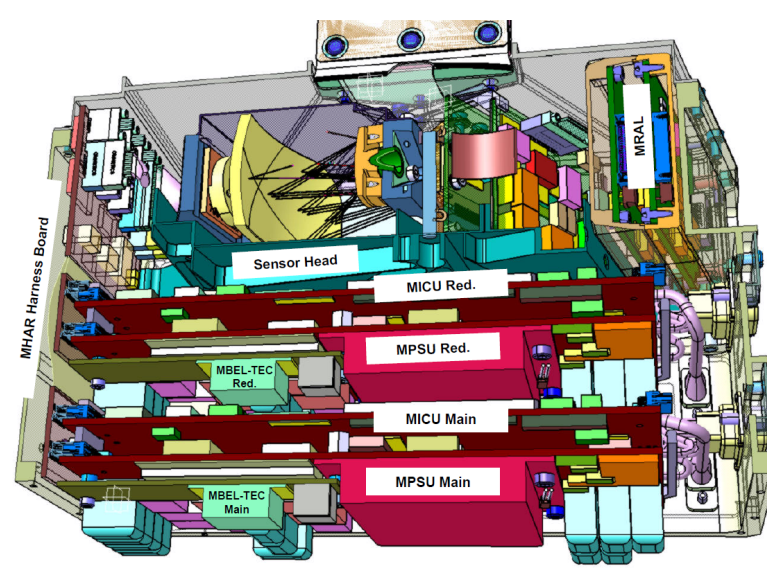

Figure 2. Instrument layout cut

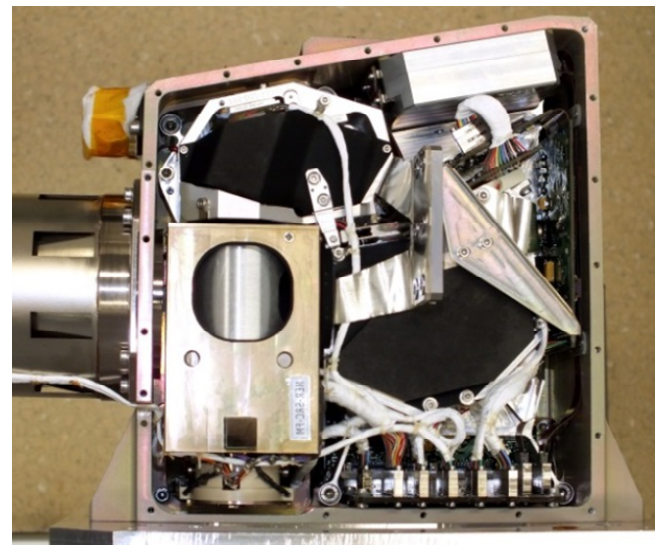

Figure 4. Flight model (FM) top view (opened)

Several innovative designs and technologies have been implemented. Core of the spectrometer is the uncooled and temperature stabilized two-dimensional bolometer ${ }^{8,10}$ array being sensitive from 7 to $14 \mu \mathrm{m}$. It images the optical window in spatial and spectral direction. The three-mirror-anastigmat (TMA) optics ${ }^{15}$ focuses the incoming optical beam on the spectrometer slit while the grating of the spectrometer optics diffracts the IR beam on the bolometer. A multilayer IR filter suppresses radiation below $7 \mu \mathrm{m}$. The radiometer detector ${ }^{7,12}$ arranges two thermo-pile lines with 15 pixels each, left and right along the spectrometer slit. Several temperature sensors are distributed over the instrument and very precise temperature measurements supports the on-ground calibration of science data.

A high reflective and high temperature resistant baffle ${ }^{14}$ suppresses unwanted stray light coming from the Mercury's surface. The high reliable miniaturized shutter ${ }^{13}$ is located behind the spectrometer's slit. It helps to extract the spectrum to be measured from the much higher IR background radiation coming from the housing. The pointing unit scans periodically the calibration and planet views. A high precision of the pointing mirror position is required to repeat the Bolometer's image position in the sub-pixel domain ${ }^{19}$. For safety reasons an emergency pointing actuator (EPA) ${ }^{18}$ is implemented moves the pointing mirror permanently to the planet view position. It is activated only in case that the 


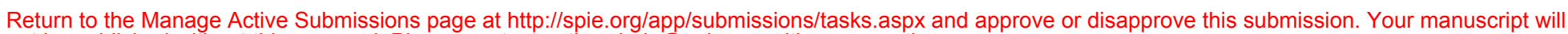
not be published without this approval. Please contact author_help@spie.org with any questions or concerns.

stepper motor of the pointing unit failed. In this case the on-board calibration is lost but data from the planet can still be acquired. For operating in Mercury's cold seasons heaters are accommodated at the sensor head. They are controlled internally by MERTIS. A single FPGA instrument controller with integrated LEON-FT processor core controls MERTIS as well as processes and compresses the science data. A single converter power unit ${ }^{11}$ supplies the subsystem with few voltages internally.

The on-board software is divided into two physical independent modules. The Primary Boot Software is stored in PROM and executes the Safe mode as well as memory management functions. The Application Software and separated parameter sets are stored in EEPROM. It performs science mode operations, data processing as well as instrument control and extended diagnostics functions.

\begin{tabular}{|c|c|c|c|}
\hline Parameter & Unit & Spectrometer & Radiometer \\
\hline Focal length & $\mathrm{F}$ & \multicolumn{2}{|c|}{$50 \mathrm{~mm}$} \\
\hline $\mathrm{F}$ - number & $\mathrm{F} \#$ & \multicolumn{2}{|c|}{2.0} \\
\hline Optical efficiency & 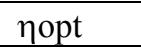 & \multicolumn{2}{|c|}{0.54} \\
\hline Spectrometer detector & Type & Bolometer array & Thermopile line array \\
\hline $\begin{array}{l}\text { Detector/pixel size } \\
\text { (detector illuminated pixels) }\end{array}$ & pixels & $\begin{array}{c}160 \times 120 @ 35 \mu \mathrm{m} \\
\text { (100 spatial, } 80 \text { spectral) }\end{array}$ & $2 \times 15 @ 250 \mu \mathrm{m}$ \\
\hline Spectral range & $\lambda$ & $7-14 \mu \mathrm{m}$ & $7-40 \mu \mathrm{m}$ \\
\hline Spectral channel width & $\lambda \delta$ & $90 \mathrm{~nm} /$ pixel & $\begin{array}{c}\text { Line array } 1: 7-14 \mu \mathrm{m} \text { (filter) } \\
\text { Line array } 2: 7-40 \mu \mathrm{m} \\
\end{array}$ \\
\hline $\begin{array}{l}\text { Spectral resolution/ } \\
\text { Spectral sampling distance }\end{array}$ & $\begin{array}{l}\lambda / \lambda \delta \\
\mathrm{SSD}\end{array}$ & $78-156$ & - \\
\hline \multirow[t]{2}{*}{ Detectivity } & $\mathrm{D}^{*}$ & - & $7 * 10^{8} \mathrm{~cm} \mathrm{~Hz}^{1 / 2} \mathrm{~W}^{-1}$ \\
\hline & NEP & $\begin{array}{c}<15 \mathrm{pW} \\
(\mathrm{SNR}>266 @ 8 \mu \mathrm{m})\end{array}$ & - \\
\hline Instantaneous field of view & IFOV & $0.7 \mathrm{mrad}$ & $5 \mathrm{mrad}$ \\
\hline Field of view & FOV & $4^{\circ} \mathrm{ACT}, 0^{\circ} \mathrm{ALT}$ & $4^{\circ} \mathrm{ACT}, 1^{\circ} \mathrm{ALT}$ \\
\hline $\begin{array}{l}\text { Ground sample distance } \\
\text { Periherm } 400 \mathrm{~km} \\
\text { Apoherm } 1500 \mathrm{~km}\end{array}$ & GSD & $\begin{array}{c}280-1400 \mathrm{~m}(\mathrm{M}=1-5) \\
1050 \mathrm{~m}\end{array}$ & $\begin{array}{l}2000 \mathrm{~m} \\
7500 \mathrm{~m}\end{array}$ \\
\hline $\begin{array}{l}\text { Dwell time } \\
\text { Periherm } 400 \mathrm{~km} \\
\text { Apoherm } 1500 \mathrm{~km}\end{array}$ & $\tau$ & $\begin{array}{l}109 \mathrm{~ms} \\
784 \mathrm{~ms}\end{array}$ & $\begin{array}{c}775 \mathrm{~ms} \\
5597 \mathrm{~ms}\end{array}$ \\
\hline Swath width & Width & \multicolumn{2}{|c|}{$28 \mathrm{~km}$} \\
\hline $\begin{array}{l}\text { Instrument overall dimensions } \\
\text { external baffles }\end{array}$ & Volume & \multicolumn{2}{|c|}{$\begin{array}{c}180 \times 180 \times 130 \mathrm{~mm}^{3} \\
200 \times ø 75 \& 90 \times ø 75 \mathrm{~mm}^{3}\end{array}$} \\
\hline Instrument mass & $\mathrm{kg}$ & \multicolumn{2}{|c|}{$3.1 \mathrm{~kg}$} \\
\hline $\begin{array}{l}\text { Instrument power consumption (incl. } \\
\text { cold case heating) }\end{array}$ & $\mathrm{W}$ & \multicolumn{2}{|c|}{$\begin{array}{c}7,9-9,9 \mathrm{~W} \text { (nominal Science operation) } \\
<14 \mathrm{~W} \text { incl. cold case heating }\end{array}$} \\
\hline Instrument data rate & KBit/s & \multicolumn{2}{|c|}{$\begin{array}{c}1-1263 \mathrm{KBit} / \mathrm{s} \\
\text { (depends on instrument mode) }\end{array}$} \\
\hline
\end{tabular}

Table 1. MERTIS FM parameters

One of the most important parameter is the single-to-noise-ratio (SNR) of the spectrometer. With a SNR of about 100 the instrument will make it possible to resolve and map low contrast mineral bands ${ }^{2,4}$. A first result after calibrating the FM spectrometer is shown in Figure 5. It represents the spectral radiance SNR of e.g. $266 @ 8 \mu \mathrm{m}$ at a target temperature of $700 \mathrm{~K}$ and a dwell time of $100 \mathrm{msec}$. The transmittance of the KRS5 entrance window of the vacuum chamber is corrected. The black body emissivity of 0.95 is considered. This SNR value is the pure optical and sensor performance. It will be increased significantly by on-board algorithms and by operating of specific measurement sequences ${ }^{17}$. MERTIS is able to do a fast averaging on-board. A minimum averaging factor is $4 @ 100 \mathrm{msec}$ which increases the SNR by factor of 2. A maximum averaging factor of $32 @ 800 \mathrm{msec}$ increases SNR by factor of 5.7. Additional improvements are foreseen by averaging of background data as well as spatial and spectral binning of the bolometer pixels. 
Return to the Manage Active Submissions page at http://spie.org/app/submissions/tasks.aspx and approve or disapprove this submission. Your manuscript will not be published without this approval. Please contact author_help@spie.org with any questions or concerns.

All this is planned to perform during operation at Mercury. A high SNR of 530...740@700K and $8 \mu \mathrm{m}$ is expected, much better than required. More results are eagerly awaited when all data are evaluated.

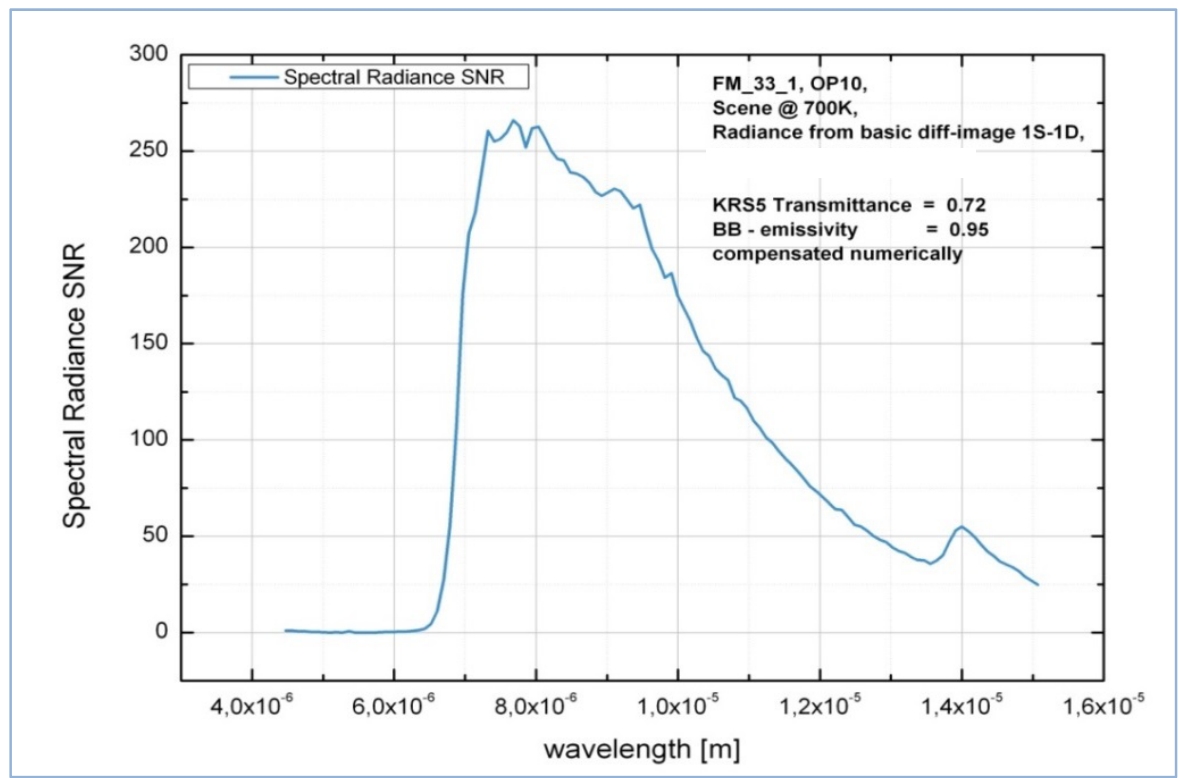

Figure 5. Spectral Radiance SNR of the FM spectrometer

\section{ADVANCED MODEL PHILOSOPY}

The development of MERTIS required a miniature design and several new technologies to be qualified starting from technology readiness level $2-5\left(\mathrm{TRL}^{20}\right)$ to get finally a TRL of 9 for the flight model (FM). Therefore it was decided to establish a classical full model philosophy, including a complete qualification model (QM) to qualify the flight design before integrating the FM. Moreover, within the study phase a risk has been identified that the miniaturized design and over ten sub-systems could not be integrated within a $3 \mathrm{~kg}$-single box. Thus a breadboard (see Figure 7) was established". Additionally, a development model (DM) (Figure 9) has been established early in the design phase. Based on it the main optical performance, the integration concept as well as mass and power could be confirmed, already representing the FM. Based on these experiences, it could be assured that the main requirements can be fulfilled two years before freezing the FM design.

The matrix in Table 2 shows the complete set of developed models, and the performance on which they have been verified. Four models have been requested by ESA. The breadboard, DM and QM were available for internal use only.

\begin{tabular}{|l|c|c|c|c|c|c|c|}
\hline \multicolumn{1}{|c|}{ Performance/Feature vs Model } & BB & DM & STM* & EM* & QM & FM* & FS (QM)* \\
\hline Optical and sensor performance & $\mathrm{x}$ & $\mathrm{x}$ & & & $\mathrm{x}$ & $\mathrm{x}$ & $\mathrm{x}$ \\
\hline $\begin{array}{l}\text { Functional and electrical interface } \\
\text { performance }\end{array}$ & & $\mathrm{x}$ & & $\mathrm{x}$ & $\mathrm{x}$ & $\mathrm{x}$ & $\mathrm{x}$ \\
\hline Feasibility about form, fit, integration & & $\mathrm{x}$ & & & $\mathrm{x}$ & $\mathrm{x}$ & $\mathrm{x}$ \\
\hline $\begin{array}{l}\text { Structural and mechanical interface } \\
\text { performance }\end{array}$ & & $\mathrm{x}$ & & $\mathrm{x}$ & $\mathrm{x}$ & $\mathrm{x}$ \\
\hline $\begin{array}{l}\text { Thermal and thermal interface } \\
\text { performance }\end{array}$ & & & $\mathrm{x}$ & & $\mathrm{x}$ & $\mathrm{x}$ & $\mathrm{x}$ \\
\hline EMC performance & & & & $\mathrm{x}$ & $\mathrm{x}$ & $\mathrm{x}$ & $\mathrm{x}$ \\
\hline $\begin{array}{l}\text { Overall performance with flight } \\
\text { component }\end{array}$ & & & & & $\mathrm{x}$ & $\mathrm{x}$ & $\mathrm{x}$ \\
\hline Calibration method \& procedures & & $\mathrm{x}$ & & & $\mathrm{x}$ & $\mathrm{x}$ & $\mathrm{x}$ \\
\hline
\end{tabular}

Table 2. Performance verification vs Model philosophy (* - requested by ESA) 


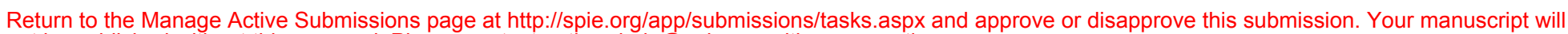
not be published without this approval. Please contact author_help@spie.org with any questions or concerns.

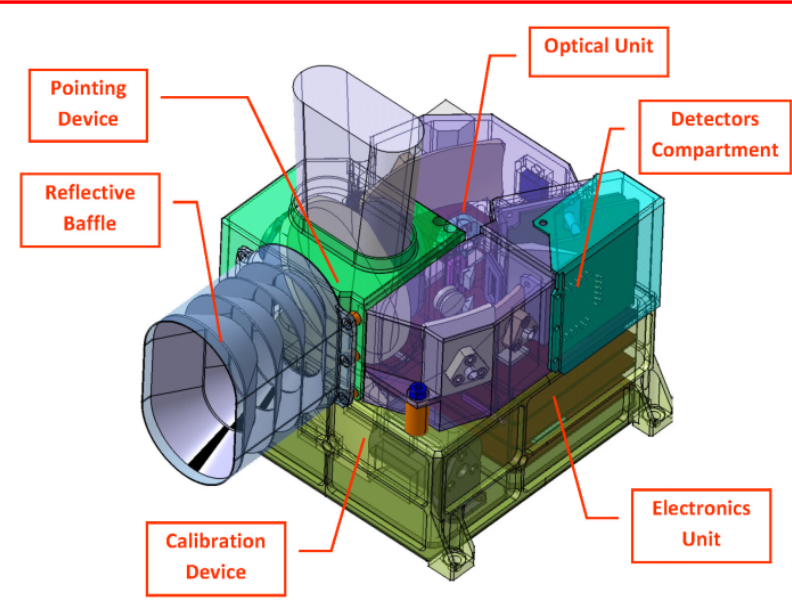

Figure 6. MERTIS as proposed in 2004

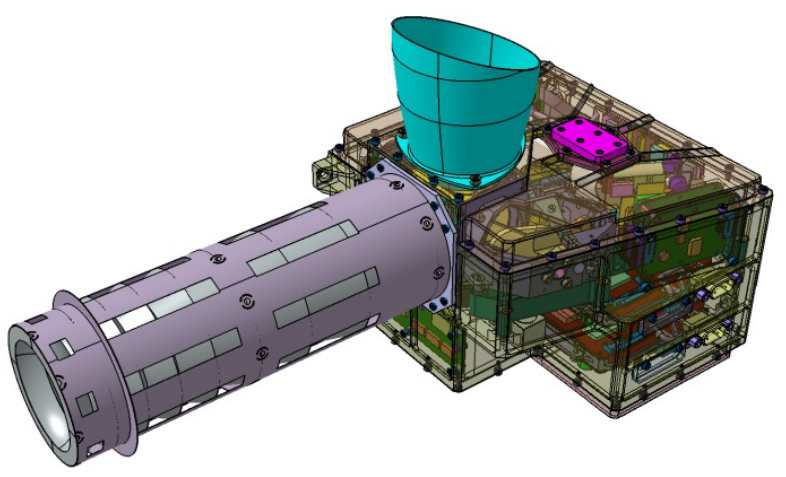

Figure 8. Design at IPDR in April 2008

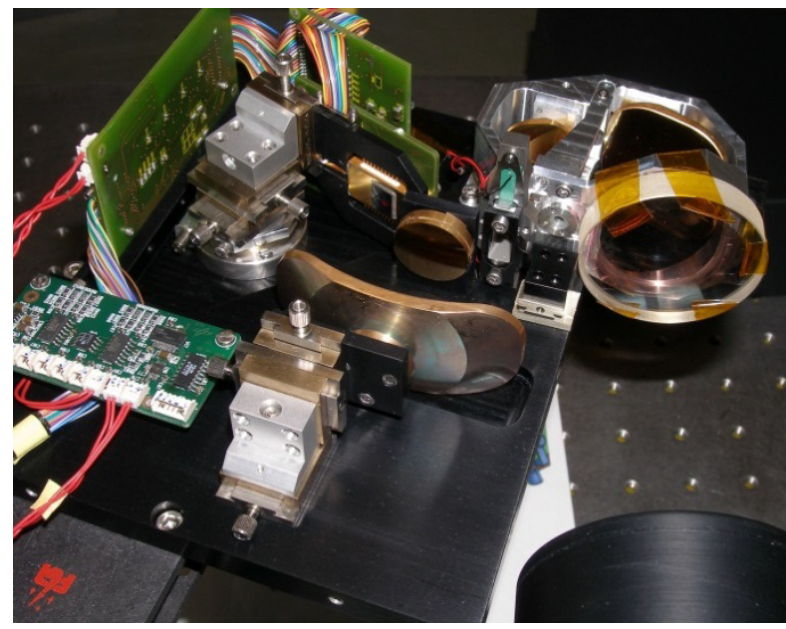

Figure 7. Optics \& electronics breadboard in 2007

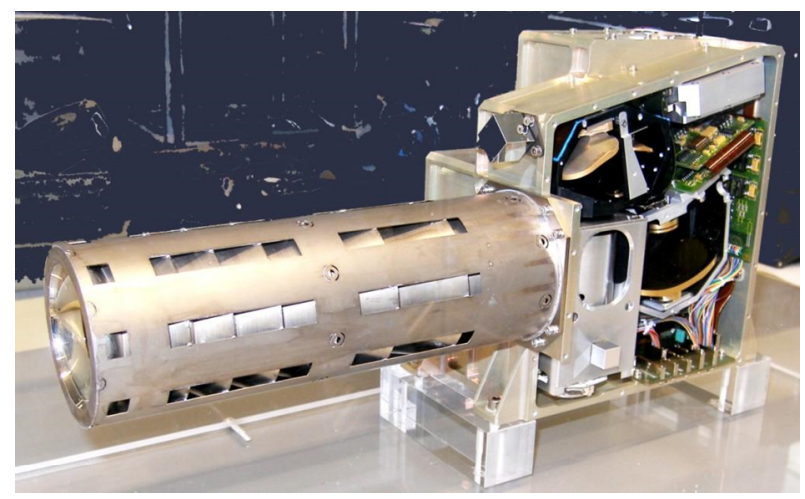

Figure 9. DM integrated in August 2009

Furthermore, significant financial resources had to be acquired from several shareholders. The financial budget was provided by the German Aerospace Center (DLR) and ESA as shown in chapter 5.

Technical resources like mass and power consumption are strongly limited for almost all space projects. One of the main aspects selecting MERTIS by ESA was small resources in respect to mass and power on one hand, but an advanced optical performance on the other hand. Usually, resources are underestimated at the beginning of the project. This often leads to following system engineering and management constrains being incalculable in terms of financially support and technical realization.

The MERTIS advanced model philosophy, especially the early developed DM, prevented exceeding the budgets. More than this, finally both mass and power are decreased during the implementation phase. At the same period the optical performance was even improved.

Figure 10 and Figure 11 show the evolution of the mass and power budget as a result of this approach. The mass increased by only $14 \%$ from the proposal stage to the real measurement for FM with $3.07 \mathrm{~kg}$.

Power consumption increased $40 \%$ to a quiet low value of $9,9 \mathrm{~W}$ only. That means the absolute relatively small power budgets were underestimated at the beginning.

The power consumption was calculated with $12.9 \mathrm{~W}$ during the design phase considering real measurements with DM. Currently, QM and FM have a power consumption of $10 \mathrm{~W}$ only. The reduction is caused by using a different FPGA type. For DM/EM the non-space qualified type from XILINX was used, for QM/FM the radiation hard type from ACTEL is implemented. This results in lower power consumption and helps to have very temperatures inside the FM considering the high temperature of the $\mathrm{S} / \mathrm{C}$. The maximum temperature is only $+60^{\circ} \mathrm{C}$ for the hottest $\mathrm{S} / \mathrm{C}$ temperature of $+45^{\circ} \mathrm{C}$ at the thermal reference point (TRP). 
Return to the Manage Active Submissions page at http://spie.org/app/submissions/tasks.aspx and approve or disapprove this submission. Your manuscript will not be published without this approval. Please contact author_help@spie.org with any questions or concerns.

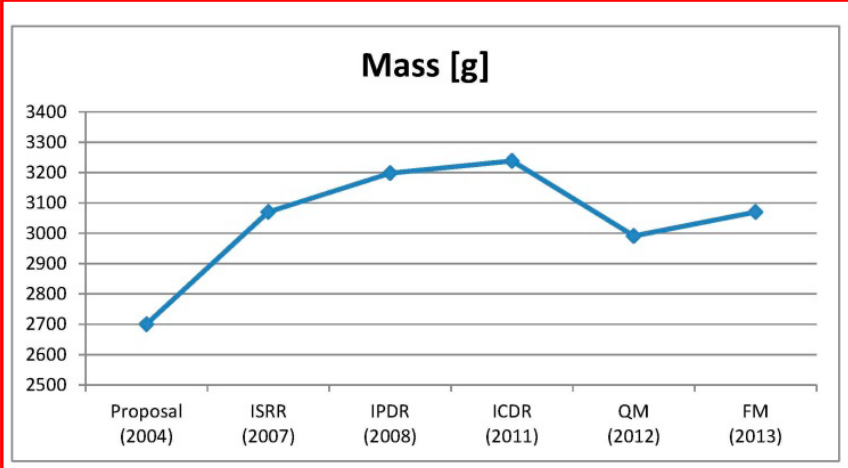

Figure 10. Mass budget evolution from proposal to the FM

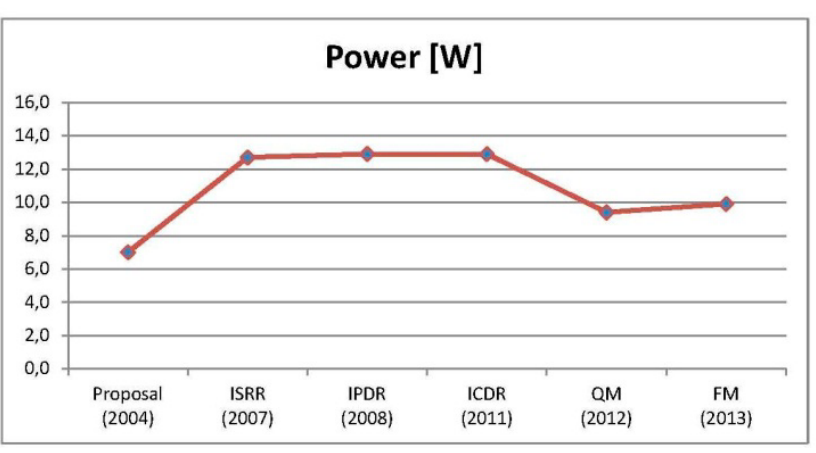

Figure 11. Power budget evolution from proposal to the FM

\section{PROJECT ORGANIZATION AND VERIFICATION APPROACH}

Based on the idea to measure the spectral Christiansen features ${ }^{2,3,4}$ at $8 \mu \mathrm{m}$ a small group of senior scientists established and won the proposal in 2005. Before, first experiences with the new uncooled bolometer technology ${ }^{8}$ were demonstrated in terrestrial applications. Theoretical bases ${ }^{16}$ and key design aspects had to be analyzed. A highly miniaturized concept seemed possible to develop. Nevertheless, an instrument with $3 \mathrm{~kg}$ only, surviving in a harsh environment at Mercury was never developed before. From the beginning of the project it was obvious that the development of such an instrument requires appropriate system engineering and project management. Both are essential for successful scientific experiments.

A specific project organization was established as follows.

a) ORG1: A planetary science and technology oriented PI/system team including the PI, physicist, management, system engineering. They focused on optical sensor performance, system design, assembly and calibration. Subsystems are developed which fulfills core science related requirements, e.g. sensor electronics.

b) ORG2: A main (medium size) industrial partner with advanced experiences in the space business. They focused on a system level verifications as an independently organization from the system designer's organization. Subsystems are developed where high quality and reliability have its highest priority, e.g. mechanical shutter actuator.

c) ORG3: Several industrial partners, which have experiences with development using specific technology, e.g. $\mathrm{CeSiC}$ mirror for the pointing unit or optics manufacturing. Experiences for developing of space applications were not necessarily needed.

d) ORG4: A small industrial partner developing an on-board and ground support software. Experience for similar space projects was required as well as flexibility.

\begin{tabular}{||l|r|}
\hline \multicolumn{1}{|c|}{ Criteria/Competence } & Weighting \\
\hline Management & $40 \%$ \\
\hline Offer consistency and completeness & $7 \%$ \\
\hline Project organization & $2 \%$ \\
\hline Cost Management/ Engineering & $7 \%$ \\
\hline Cost Manufacturing/ Verification & $4 \%$ \\
\hline Cost Total & $20 \%$ \\
\hline Manufacturing & $11 \%$ \\
\hline Sub-System A development & $3 \%$ \\
\hline Sub-System B development & $3 \%$ \\
\hline Sub-System C development & $5 \%$ \\
\hline
\end{tabular}

\begin{tabular}{|l|r|}
\hline \multicolumn{1}{|c|}{ Criteria/Competence } & Weighting \\
\hline Engineering & $34 \%$ \\
\hline IR Optics Engineering/ Analysis & $10 \%$ \\
\hline Sub-System A design & $5 \%$ \\
\hline Sub-System B design & $4 \%$ \\
\hline Thermal Engineering/ Analysis/Test & $10 \%$ \\
\hline Structure Analysis/Test & $3 \%$ \\
\hline Quality Assurance/ EEE Parts Procurement & $2 \%$ \\
\hline Heritage & $15 \%$ \\
\hline System Engineering/ Management & $10 \%$ \\
\hline Engineering/ Verification Optics & $5 \%$ \\
\hline
\end{tabular}

Table 3. Assessment table for selection of industrial partner for the design phase 


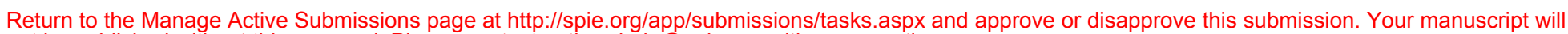
not be published without this approval. Please contact author_help@spie.org with any questions or concerns.

Industrial partners were selected after finishing the study phase. Assessment criteria and their weighting for the main industrial organization are shown in Table 3.

This cooperation has several advantages. First; the system design developed by ORG1 is verified by an independent organization ORG2. All critical analysis and verification tasks have been performed by ORG2, i.e. thermal analyses and test, structural analysis and tests, EMC tests, optical design analysis. The result is a highly verified design and manufactured models. Finally a significant reduction of development risk has been achieved.

A second important point is that two teams work in parallel on nearly the same aspects but with different methods. One team designs the instrument, another one verifies the design. They are able to exchange knowledge and improve the design step by step.

\section{COST OF SYSTEM DEVELOPMENT}

Developing scientific instruments with new technologies means often unpredictable or underestimated costs at the beginning. This can result in a high cost overrun. Furthermore the project success depends on having enough resources especially at late project phases. Particularly the calibration of a thermal infrared instrument is an essential task at the end of the project. Missing resources and time often induce e.g. a less qualified "last minute and low budget calibration". Shortcomings in the instrument's preflight onground calibration result in a decrease of the scientific instrument performance. This is one of the highest risks from the scientist's point of view.

Knowing the real costs needed for development in an early stage of the project helps to put it on a solid financial basis. Furthermore it is essential to meet stakeholder's financial requirements.

This chapter gives an overview about cost prediction at the project beginning including the study phase in 2005 and compares to the total cost status today in 2013. The cost distribution of involved European organizations has been analyzed. Key questions are: "what are the cost to completion?" and "was the project within the predicted budget?".

The costs shown in Figure 12 and Figure 13 are full market expenses. They cover all study, design and development phases up to the integration and tests on satellite level and this distributed over all scientific and industrial organizations in Germany, Poland and ESA. The budget does not include the sheer Mercury science tasks of the involved scientists.

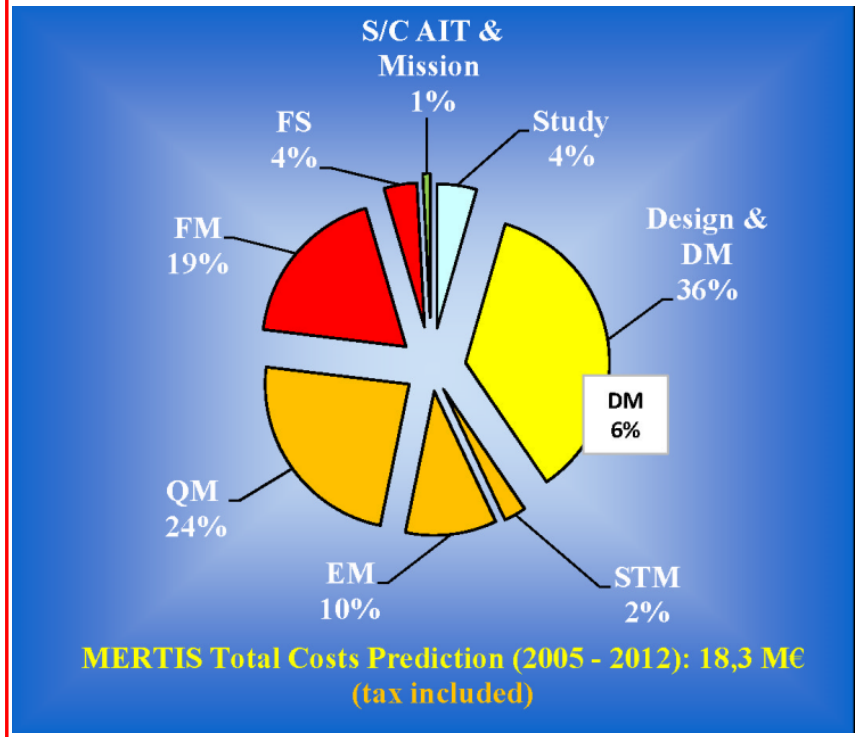

Figure 12. Total costs predicted in 2005

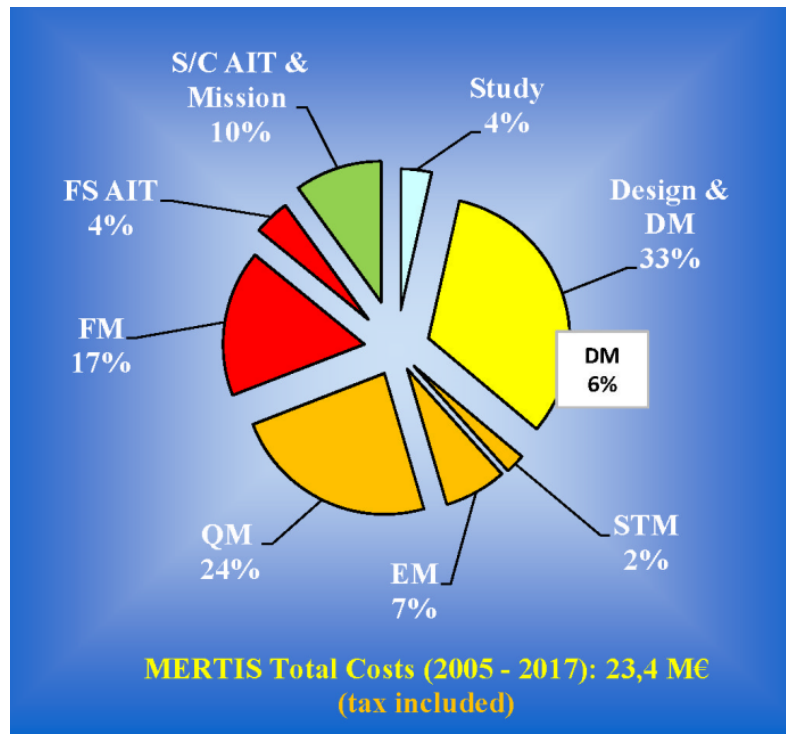

Figure 13. Total costs as is in 2013

Figure 12 shows the costs predicted in 2005 for a project schedule from 2005 until 2012 including a margin of $20 \%$ and including taxes. The costs over several development phases and models are separated. Within the proposal in 2004 the launch was planned in 2012 and MERTIS was proposed to the stakeholders with a budget of $18.3 \mathrm{M} €$. Unfortunately, the BepiColombo schedule was shifted several times. Today the launch is planned for 2016, i.e. about 4 years later than initially planned in 2004 . 
Return to the Manage Active Submissions page at http://spie.org/app/submissions/tasks.aspx and approve or disapprove this submission. Your manuscript will not be published without this approval. Please contact author_help@spie.org with any questions or concerns.

Figure 13 presents the status of total costs of 23.4M€ in 2013. This includes the project life time until commissioning after launch over almost 12 years, from 2005 until 2017. There is a cost overrun of about $28 \%$ compared to the total costs predicted in 2005 and as it is in 2013. Analyzing the cost positions more deeply the reasons for this cost increasing are the following:

Mainly two aspects increased the costs. (a) A growth of $24 \%$ within the past 12 years is caused by inflation. Additionally, the tax in Germany increases from $16 \%$ to $19 \%$ in 2007. (b) Another increase within the development was an underestimated budget for satellite AIT activities after FM completion with about $10 \%$ of the total costs.

Considering these aspects of inflation and tax increase and the fact that BepiColombo delays for about 4 years, the MERTIS development was nearly within the financial budget as predicted in 2005. Much higher supporting costs for satellite AIT and pre-launch activities brought a real cost overrun. Nevertheless the absolute costs are comparably low or even lower than similar developments of other ESA missions.

\section{SCHEDULES AND CONSTRAINS}

A reliable schedule is always a challenge even if there is sufficient time for development. Unexpected problems worsen the schedule situation. The team becomes overstressed resulting in lower quality of the work.

Some aspects were considered to avoid such a scenario. Two of them are of special importance for MERTIS. One is the presents of the development model (DM, compare above). With the early available DM the team was able to learn how the performance looks like within an integrated system. Calibration methods were started to learn about 3 years before the FM had to be calibrated. Even if the DM is not fully representative, with the flight design methods were proved and procedures established.

Based on these experiences the FM schedule could be gained by several months and predicted with an acceptable uncertainty. The "as done" schedule is shown in Figure 14. During all phases MERTIS was always the first or one of the first instruments delivered to ESA. 5 months were predicted and needed for the FM calibration. This was sufficient time - a very comfortable situation for the whole team.

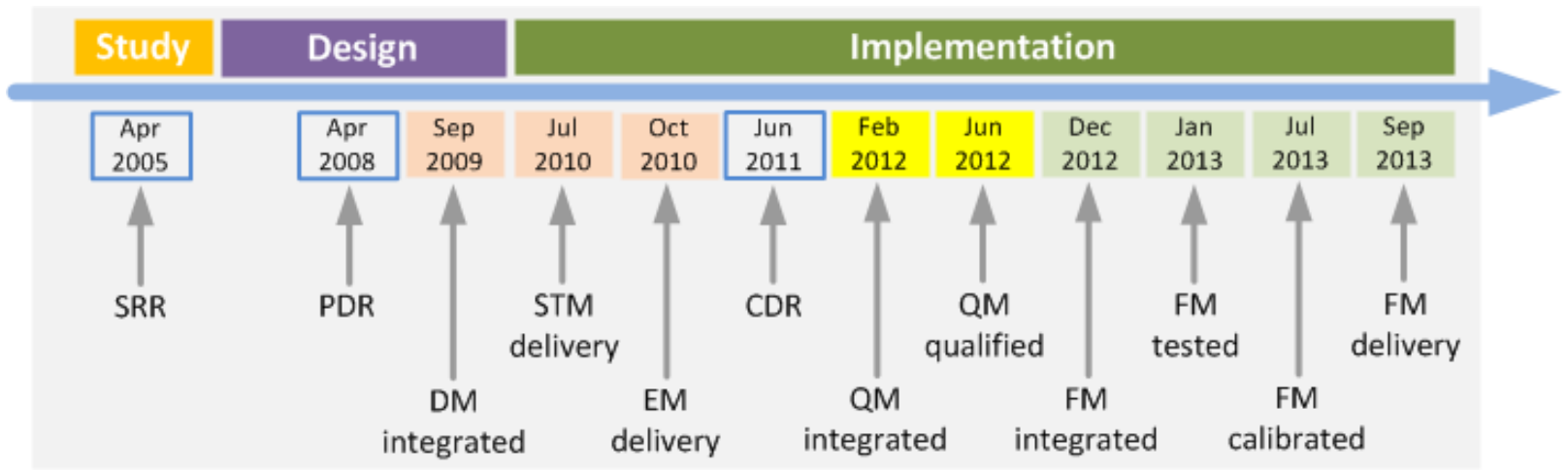

Figure 14. MERTIS Milestones 2005 - 2013

A second aspect focuses on the shortening of measuring and test times using complex laboratory setups. A specific concept of on-board and on-ground operation has been established. It allows reducing the time needed for measuring and operating of MERTIS. Several dedicated and complex laboratory setups had to be operated with different models in parallel. Time needed for system testing, radiometric and geometric calibration of the spectrometer and radiometer is considerable. About $80 \%$ of these activities had to be performed in vacuum.

The on-board and on-ground operation and software concept includes:

$\rightarrow$ Calibration of all telemetry housekeeping online on-board except the science data itself

$\rightarrow$ Separation of on-board software code and parameters independently unloadable from ground

$\rightarrow$ Automation of measurement and tests

$\rightarrow$ Use of only one common data base as source for on-board an on-ground operation 
Return to the Manage Active Submissions page at http://spie.org/app/submissions/tasks.aspx and approve or disapprove this submission. Your manuscript will not be published without this approval. Please contact author_help@spie.org with any questions or concerns.

Usually housekeeping parameters and science telemetry data are sent to ground as raw data. They are calibrated off-line on ground by the user with a large set of parameters. Parameter sets are different for each model. Each user has to handle several sets of parameter configurations for analyzing the data. Mistakes can happen, configuring the measurements and data processing takes time and manpower resources. In worst case measurements and tests have to be repeated.

In MERTIS all housekeeping are calibrated on-board. For correct science data interpretation high precise temperatures, voltages, etc. are needed. At telemetry the user gets parameters in SI units only. For each model it is the same data interface. The user does not need to know how they are processed and calibrated in MERTIS.

All parameters used on-board are not compiled in software together with the software code. They are permanently stored in a separate parameter file in EEPROM. The main and redundant channels of each model have its own parameter file. It can be uploaded separately from ground to MERTIS. This ensures that each model has identical on-board software. Only different parameter configurations are used. On the other hand the software can be updated without changing the individual parameter set.

Only one data base exists in which all parameters are stored as a core of the electrical ground support equipment (EGSE). From here the on-board parameter sets are exported. In addition this data base is the source for ESA's data base SCOS $2000^{23}$ for operating MERTIS during the S/C AIT phase and in orbit.

Moreover, the time consuming measurements and test procedures are automated. A high reproducibility and much shorter execution times were achieved. National instruments TestStand ${ }^{21}$, as a tool for test automation and the TDMS ${ }^{22}$ file format are used for storing the data. Data from MERTIS and from the on-ground laboratory system are located in one common data file with time stamps to correlate the data to each other.

All these measures saved time and increased the quality for data analysis. Of course, additional software developer resources must be available long before measurement and tests had to be performed. The resources needed for software development are not higher than those are needed to operate such complex laboratory setups.

\section{LESSONS LEARNT AND CONCLUSION}

There are different approaches to implement management and system engineering methods optimizing a deep space instrument development to make the project success. We would like to summarize our lessons learnt. These were in general positive experiences.

Base of the project success was a proposal with an innovative detector, optics and architecture design. Key design aspects were stable from the beginning of the project, now implemented in the flight model.

Defining an advanced model philosophy is one of the most important tasks for the management and system engineering. It allows to establish a more predictable schedule and to reduce the project risks significantly. For MERTIS the development model played a crucial role. It was established early in the design phase. During the design phase the challenge was to build a model that represents already the flight model design as close as possible. The DM focus was the core optical performance, the overall design and electrical interfaces as the most representative parts. All sub-systems with whole functionality were implemented without redundancies. The optical performance was studied, corresponding calibration methods evaluated. The DM has been used over the whole program in all phases as a functional model, e.g. for developing and testing on-board software and EGSE as well. Nevertheless it could be disassembled and assembled for modifying components without programmatic constrains. The potential increase of a small portion of cost (i.e. $6 \%$ of total cost) is negligible related to the advantages shown at the end of the project.

Challenging projects have an expensive qualification model (QM) with flight standard. To save costs the proto flight approach is sometimes requested but not possible to do with such a program as BepiColombo and MERTIS was. If a refurbishment of the QM to a flight spare model (FS) is done, the costs are acceptable. For the MERTIS development the QM was a need. During the qualification some sub-systems failed, e.g. the pointing mirror was broken; isolation issues were detected due to the high integration density. The QM could not be used as a flight spare model. Pre-damages caused by the high vibration levels prevented the originally indented approach. Building up a new flight spare model became necessary, integrated with spare modules available from FM manufacturing.

With the MERTIS model philosophy a lot of models need to be developed and operated. Approximately one year was necessary to build and test a model. It was important to develop the models for internal use on schedule, not only the 
Return to the Manage Active Submissions page at http://spie.org/app/submissions/tasks.aspx and approve or disapprove this submission. Your manuscript will not be published without this approval. Please contact author_help@spie.org with any questions or concerns.

models to be delivered. If a model is postponed or not properly tested the experience e.g. measuring with this model wanted to have is missing.

The on-board and on-ground software concept helped although it cost resources for the development. Complex laboratory setups could be operated with several models in parallel. The resources needed for operation, tests and measurements could be significantly reduced.

The approach that the verification is done by an independent industrial oriented organization has more than one advantage. It improves the design quality and the verification coverage is high. The engineers, responsible for design on the one hand and modeling or testing on the other hand, complement their expertise on a methodical level.

The compilation of the partners involved, such as scientific institutions, small and medium-sized industrial enterprises has been proven.

The summary is:

$\rightarrow$ The science and technical requirements are fulfilled and exceeded. The FM is well calibrated and finally the presented optical performance is better than initially planned. Mass and power are lower than required by ESA.

$\rightarrow$ The delivered MERTIS models were always on schedule. They were shipped as first or one of the first scientific instruments to ESA.

$\rightarrow$ MERTIS was developed almost within the predicted budgets. Only the cost after delivery of the FM for AIT on Spacecraft level was significant underestimated at the proposal stage.

\section{AKNOWLEDGMENTS}

We acknowledge the work of the entire MERTIS team with contributions of the Institut für Planetologie of the Westfälische Wilhelms-Universität Münster, the DLR Institute of Planetary Research, Berlin, the DLR Institute of Optical Sensor Systems, Berlin, Kayser-Threde Munich, Fraunhofer Institute for Applied Optics and Precision Engineering, Jena, Ingenieurbüro Ulmer, Frankfurt/Oder, Astro- und Feinwerktechnik, Berlin, and the Polish Academy of Science, Warsaw. Many thank the German Space Center (DLR) and ESA for funding the project and the ESA' project team for their efficient helps having MERTIS on BepiColombo.

\section{REFERENCES}

[1] Benkhoff, J., van Casteren, J., Hayakawa. H., Fujimoto, M., Laakso, H., Novara, M., Ferri, P, Middleton, H., Ziethea, R., "BepiColombo - Comprehensive exploration of Mercury: Mission overview and science Goals," Planetary and Space Science Volume 58, 2-20 (2010)

[2] Arnold, G. E., Helbert, J., Hiesinger, H., Hirsch, H., Jessberger, E. K., Peter, G., Walter, I. and the MERTIS-Team, "MERTIS - MErcury Radiometer and Thermal Infrared Spectrometer- a novel thermal imaging spectrometer for the exploration of Mercury," Proc. SPIE Journal of Applied Remote Sensing 2, (2008).

[3] Arnold, G. E., H. Hiesinger H., J. Helbert J., Paproth C., Säuberlich T., Peter G., Walter I., "Thermal infrared imaging of Mercury - MERTIS a new remote sensing Technology," Proc. SPIE 7453, (2009).

[4] Hiesinger, H., J. Helbert, "The Mercury Radiometer and Thermal Infrared Spectrometer (MERTIS) for the Bepi Colombo Mission," Planetary and Space Science Volume 58, 144-165 (2010)

[5] Helbert, J., Hiesinger, H., Walter, I., Säuberlich, T., Maturilli, A., D’Amore, M., Knollenberg, J., Lorenz, E., Peter, G., Arnold G., "MERTIS: understanding Mercury's surface composition from mid-infrared spectroscopy," Proc. SPIE 7808, (2010).

[6] Helbert, J., Hiesinger, H., D'Amore, M., Walter, I., Säuberlich, T., Peter, G., Arnold G., Maturilli, A., "MERTIS on BepiColombo: seeing Mercury in a new light," Proc. SPIE 8867, (2013).

[7] Walter, I., Zeh, T., Helbert, J., Hiesinger, H., Hirsch, H., Knollenberg, J., Kessler, E., Rataj, M., Habermeier, J., Peter, G., "Deep space instrument design for thermal infrared imaging with MERTIS," Proc. SPIE 8154, (2011). 
Return to the Manage Active Submissions page at http://spie.org/app/submissions/tasks.aspx and approve or disapprove this submission. Your manuscript will not be published without this approval. Please contact author_help@spie.org with any questions or concerns.

[8] Tissot, J.L., Vilain, M., Crastes, A., Tinnes, S., Larre, A., Legras, O., Yon, J.J., "Uncooled IRFPA with high performance and low thermal time constant," Proc. SPIE 5612, Defence \& Security London, (2004).

[9] Saeuberlich, T., Lorenz, E., Skrbek, W., "Conception and state of the radiometric analysis breadboard (RAB) for the Mercury Radiometer and Thermal Infrared Spectrometer (MERTIS),"Proc. SPIE 6297, (2006)

[10] Raubaud, W., Vilain, M., Garret, T., Hopkinson, G., Bentley, M. S., Kraft, S., Legras, O., Castelein, P., "Uncooled detector development for space application, ,Proc. SPIE 6958, (2008)

[11]Zeh, T., Preißler, G., Peter, G., Venus, H., Walter, I., Zender, B., Helbert, J., Multhaup, K., Hiesinger, H., "Power Supply Design for the Mercury Thermal Infrared Spectrometer MERTIS," ESPC, 2008

[12]Zeh, T., Kaiser, S., Lenfert K., Peter, G., Walter, I., Hirsch, H., Knollenberg, J., Helbert, J., Multhaup, K., Hiesinger, H, Gebhardt, A., Risse, S., Damm, C., Eberhardt, R., Baier, V., Keßler, E., "Thermal Infrared Spectrometer MERTIS for the Bepicolombo mission to Mercury," ICSO - 7th International Conference on Space Optics, (2008)

[13] Manhart, M., Zeh, T., Preißler, G., Hurni, A.., Peter, G., Walter, I., Helbert, J., Multhaup, K. and Hiesinger, H., "Design and Manufacture of a Highly Reliable, Miniaturized and Low Mass Shutter Mechanism," 40th Aerospace Mechanisms Symposium NASA/CP-2010-216272, p.335 (2010)

[14]Zeh, T., Glier, M., Peter, G., Walter, I., Helbert, J., "MERTIS: reflective baffle design and manufacturing," Proc. SPIE 7808, (2010).

[15] Gebhardt, A., Steinkopf, R., Scheiding, S., Risse, S., Damm, Ch., Zeh, T., Kaiser, S. , "MERTIS: optics manufacturing and verification," Proc. SPIE 7808, (2010).

[16] Paproth, C., Säuberlich, T., Jahn, H., Helbert, J., "MERTIS: system theory and simulation," Proc. SPIE, 7808, (2010).

[17] Saeuberlich, T., Paproth, C., "MERTIS: configuration of measurement sequences for a maximized image SNR,"Proc. SPIE 8154, (2011)

[18] Rataj, M., Pietrzak, R., Wawer, P., "Emergency Pointing Actuator (EPA) Release Mechanism of the Pointing Unit in the MERTIS BepiColombo Experiment," Proc. 14th European Space Mechanisms \& Tribology Symposium ESMATS, (2011)

[19] Walter, I., Saeuberlich, T., Lieder, Rataj, M., Driescher, H., Habermeier, J., M., Helbert, J., Hiesinger, H., "Pointing and Spectral Assignment Design and Control for MERTIS," Proc. SPIE 8867, (2013).

[20]ESA, "TRL Handbook," TEC-SHS/5551/MG/ap, (2008)

[21] National Instrument, "TestStand," www.ni.com/teststand

[22] National Instruments, "TDMS file format," www.ni.com/white-paper/5696/en

[23] ESA, "SCOS-2000, generic mission control system software of ESA," http://www.egos.esa.int/portal/egosweb/products/MCS/SCOS2000/

[24] Arnold, G.E, "Exploring the solar system: the view of planetary surfaces with VIS/IR remote sensing methods," Proc. SPIE 8154, (2011).

[25] Arnold, G.E., et al., "A new perspective on Mercury's surface composition and temperatures - Mercury Radiometer and Thermal Infrared Spectrometer (MERTIS)," Proc. SPIE 8154, (2011).

[26]ESA, "SpaceWire interface standard,", http://www.spacewire.esa.int 